\title{
Upper Extremity Dysfunction
}

National Cancer Institute

\section{Source}

National Cancer Institute. Upper Extremity Dysfunction. NCI Thesaurus. Code C78659.

Impaired functioning of the upper extremity. 